\title{
Impact of Dysphagia Assessment and Management on Risk of Stroke-Associated Pneumonia: A Systematic Review
}

\author{
Sabrina A. Eltringham ${ }^{a, b}$ Karen Kilner ${ }^{b} \quad$ Melanie Gee $^{b} \quad K^{b}$ aren Sage ${ }^{b}$ \\ Benjamin D. Bray ${ }^{c}$ Sue Pownalla,b Craig J. Smith ${ }^{d, e}$ \\ ${ }^{a}$ Department of Speech and Language Therapy, Sheffield Teaching Hospitals NHS Foundation Trust, Sheffield,

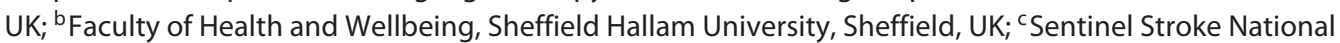 \\ Audit Programme, Royal College of Physicians, London, UK; ${ }^{d}$ Greater Manchester Comprehensive Stroke \\ Centre, Manchester Academic Health Science Centre, Salford Royal Foundation Trust, Salford, UK; e Division of \\ Cardiovascular Sciences, University of Manchester, Manchester, UK
}

\section{Keywords}

Acute stroke · Dysphagia · Stroke-associated pneumonia

\section{Abstract}

Background: Patients with dysphagia are at an increased risk of stroke-associated pneumonia. There is wide variation in the way patients are screened and assessed during the acute phase. The aim of this review was to identify the methods of assessment and management in acute stroke that influence the risk of stroke-associated pneumonia. Studies of stroke patients that reported dysphagia screening, assessment or management and occurrence of pneumonia during acute phase stroke were screened for inclusion after electronic searches of multiple databases from inception to November 2016. The primary outcome was association with stroke-associated pneumonia. Summary: Twelve studies of 87,824 patients were included. The type of dysphagia screening protocol varied widely across and within studies. There was limited information on what comprised a specialist swallow assessment and alternative feeding was the only management strategy, which was reported for association with

\section{KARGER}

(c) 2018 S. Karger AG, Basel

E-Mail karger@karger.com

www.karger.com/ced stroke-associated pneumonia. Use of a formal screening protocol and early dysphagia screening (EDS) and assessment by a speech and language pathologist (SLP) were associated with a reduced risk of stroke-associated pneumonia. There was marked heterogeneity between the included studies, which precluded meta-analysis. Key Messages: There is variation in the assessment and management of dysphagia in acute stroke. There is increasing evidence that EDS and specialist swallow assessment by an SLP may reduce the odds of stroke-associated pneumonia. There is the potential for other factors to influence the incidence of stroke-associated pneumonia during the acute phase.

(c) 2018 S. Karger AG, Basel

\section{Introduction}

Stroke-Associated Pneumonia (SAP) incorporates the spectrum of lower respiratory tract infections within the first 7 days after stroke onset [1]. It is one of the most common post-stroke infections, affecting 14\% of patients [2], and is associated with an increased risk of hospital 
mortality [3], prolonged hospital stay [4] and associated healthcare costs [5]. The timing of SAP reflects the complex relationship between infection and inflammatory responses, which may precede and develop post stroke. Respiratory infections frequently trigger ischemic stroke and worsen in the days that follow [6]. Brain-induced immunodepression and aspiration related to impaired consciousness and dysphagia [7] increase vulnerability to SAP in the acute phase after stroke.

Incidence of dysphagia in stroke patients varies widely depending on patient characteristics, variations in study design, type and severity of stroke, time of assessment and diagnostic techniques [8]. In acute stroke, the incidence ranged between 37 and $78 \%$ depending on the assessment method; lower incidence was detected using an initial screening test (37-43\%) compared to clinical assessments (30-55\%) and videofluroscopy (VFS; 64-78\%) [8].

Early identification of dysphagia post stroke informs decisions regarding nutritional management and may reduce pulmonary complications. Multiple national and international guidelines [9-13] recommend that people with acute stroke have their swallow screened by an appropriately trained healthcare professional, using a validated screening tool and remain nil by mouth (NBM) until a swallow screen is completed. The recommended time from admission to screen ranges from within $4[9,12]$ to $24 \mathrm{~h}$ [11]. If dysphagia is suspected, the person should be referred to a healthcare professional with expertise in swallowing to have a specialist assessment. This usually comprises a cranial nerve examination, trials of different diet and fluid textures and compensatory strategies. Those with suspected aspiration should be reassessed for instrumental examination using techniques such as VFS or Flexible Endoscopic Evaluation of Swallowing (FEES) $[9,10]$. Results from these assessments inform management which may include: NBM with alternative nutrition if swallowing is unsafe, diet or fluid modification, compensatory strategies or muscle strengthening exercises.

There is a wide variation in dysphagia screening protocols (DSP) and no consensus exists on the optimal DSP [14]. Most speech and language pathologists (SLPs) apply their clinical reasoning to tailor their bedside assessment over using a standardised assessment [15] such as the Mann Assessment of swallowing ability [16]. To complicate matters further, the terminology describing DSPs and bedside clinical assessments is often used inconsistently and interchangeably [12].

The aim of this systematic review was to answer the question "How do methods of dysphagia screening, assessment and management during the first $72 \mathrm{~h}$ of ad- mission affect the risk of SAP?" The objective was to identify the methods that influence the risk of SAP. A search of the National Institute for Health Research Centre for Reviews and Dissemination (NIHR CRD) Database [17] was undertaken to check whether there were existing or ongoing reviews, which addressed this question.

\section{Methods}

\section{Search Strategy and Selection Criteria}

A systematic review was undertaken according to the Preferred Reporting Items for Systematic Reviews and Meta-Analyses statement and Centre for Reviews and Dissemination guidance $[18,19]$. A building block [20] approach identified search terms for each concept which were added using the Boolean AND operator. Two search strategies were used to develop the search terms; National Clinical Guideline for Stroke [9] and the PISCES (Pneumonia in Stroke Consensus) Group [1]. Co-authors (S.P., K.S., and M.G.) reviewed the search strategy (online suppl. Appendices; for all online suppl. material, see www.karger.com/doi/10.1159/000492730). Electronic databases were searched from inception for relevant studies: CINAHL (via EBSCOhost to 19/11/16), COCHRANE (via Wiley Online to 23/11/16), EMBASE (via NICE Healthcare Databases to 23/11/16), MEDLINE (via EBSCOhost to 19/11/16) and SCOPUS to $23 / 11 / 16$. In addition, references and citations of included studies were screened.

The review was restricted to peer-reviewed English language stroke research, which evaluated dysphagia screening, assessment or management within the first $72 \mathrm{~h}$ of admission to hospital, and recorded frequency of SAP. The time restriction of $\leq 72$ $\mathrm{h}$ might not be explicit in the title/abstract; therefore, if the abstract met all the other inclusion criteria, it was included in the next stage of the screening process. Non-stroke or mixed population, studies of exclusively intubated and mechanically ventilated patients or where dysphagia assessment or management was beyond $72 \mathrm{~h}$ were excluded and studies not documenting SAP or pneumonia post stroke or pre-existing pneumonia were also excluded.

Two authors independently applied the inclusion/exclusion criteria to titles and abstracts for eligibility (online suppl. Appendices). Differences were forwarded to a third author for consensus. Abstracts that met the inclusion criteria were recommended for full-text reading. S.A.E., S.P., and K.S. screened 10\% of articles recommended and any differences were agreed by consensus. S.A.E. assessed remaining articles.

\section{Data Abstraction and Analysis}

S.A.E. piloted and designed a data extraction form base on Royal College of Physicians National Clinical Guideline for Stroke [21] and independently extracted data for the titles. Data extraction included study design and baseline characteristics of the population, as well method of screening, assessment and management, rate and association with pneumonia (online suppl. Appendices). Quality Assessment tools [22,23] were used to appraise the studies for risk of bias (online suppl. Appendices).
98

Cerebrovasc Dis 2018;46:97-105 DOI: $10.1159 / 000492730$
Eltringham/Kilner/Gee/Sage/Bray/ Pownall/Smith 
Fig. 1. Search methodology and outcome.

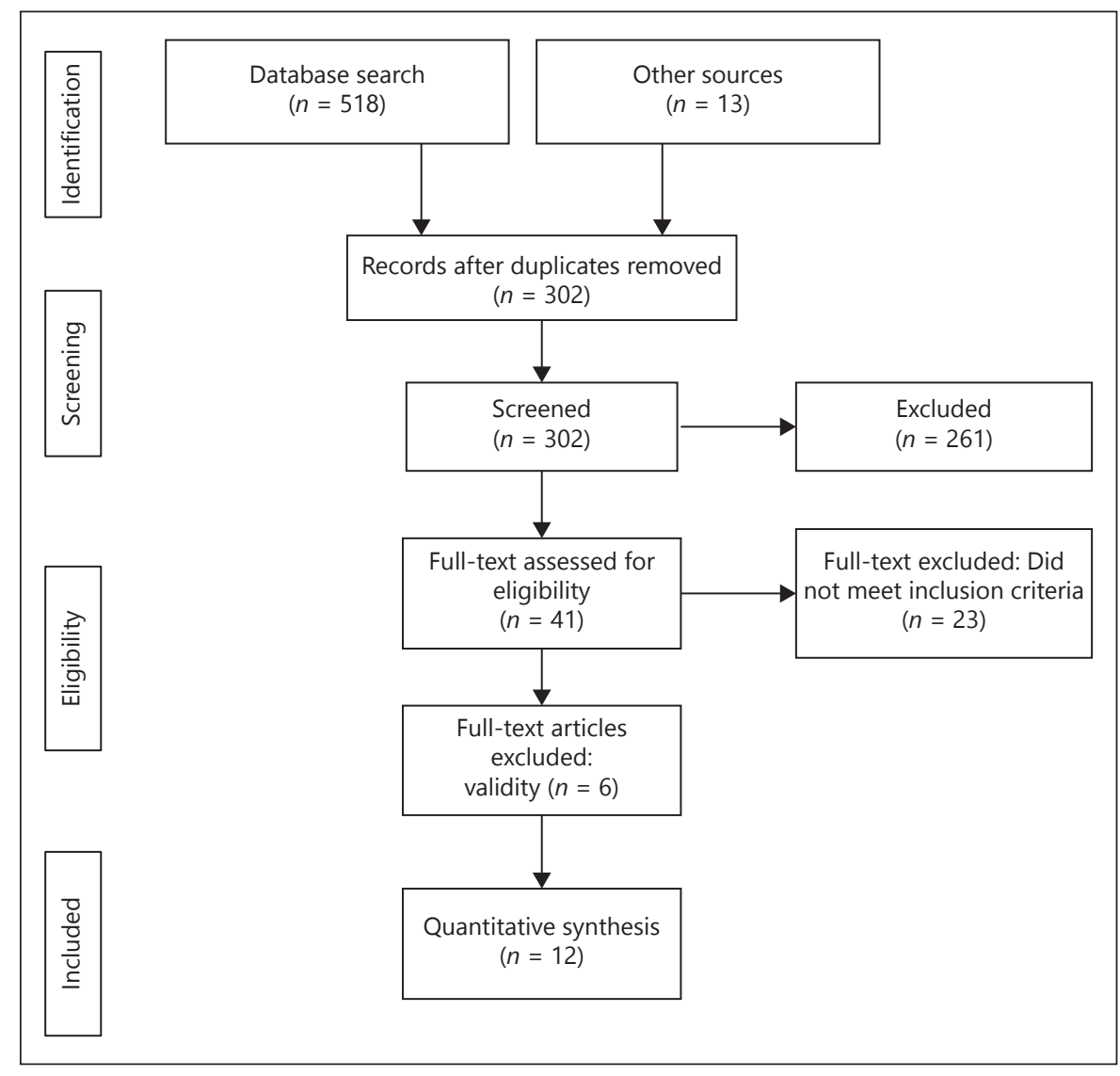

\section{Statistical Analysis}

Inter-rater reliability was analysed using the Kappa statistic. Heterogeneity was evaluated using random effects models [24]. Given that substantial heterogeneity was expected, further metaanalysis was not anticipated. Microsoft Excel produced forest plots for illustration only [25].

\section{Results}

Searching databases yielded 518 references and 13 arose through other sources (Fig. 1). Inter-rater reliability for the inclusion/exclusion criteria was 0.71 . Fortyone full-text articles were assessed for eligibility. Twelve studies with a total of 87,824 ischaemic and haemorrhagic stroke patients were included (Table 1). The majority were prospective observational studies, of which 5 were registry based [26-30]. Two used a quasi-experimental design; [31,32] and post-intervention data are reported (Fig. 2). There was one retrospective review [33]. Europe $[26-28,31,32,34]$ hosted $50 \%$ of studies, United States $25 \%[29,35,36]$ and the remainder were in Chile [33],
Japan [37] and Canada [30]. Stroke severity was reported in 7 studies using the National Institutes of Health Stroke Scale. There was variation in the way participant characteristics such as age and the National Institutes of Health Stroke Scale were reported and missing information, which precluded doing any summary statistics. One study [28] accounted for $72 \%$ of the combined population of studies, making measurement of mean statistically inappropriate. Marked variation in study design, reporting of participant characteristics and the dominance of one study prohibited meta-analysis.

Most studies controlled selection bias by consecutive recruitment of patients that met eligibility criteria and screening of all patients on admission [26-32, 35, 36]. There was still potential for bias dependent on the actual rate of screening. One study screened only patients considered at risk of dysphagia [33], while in another, it was unclear how the cohort was recruited [37]. Performance bias is also likely to have influenced reported findings. Potential risk for measurement bias exists because of heterogeneity in methods of dysphagia intervention, and variation in the way SAP was diagnosed. The criterion for 
Table 1. Study characteristics

\begin{tabular}{|c|c|c|c|c|}
\hline Study & $\begin{array}{l}\text { Design, setting, } \\
\text { country }\end{array}$ & Stroke type & Participants & Time of screen \\
\hline $\begin{array}{l}\text { Al-Khaled et al. } \\
{[26], 2016}\end{array}$ & $\begin{array}{l}\text { Prospective } \\
\text { observational, } \\
\text { Germany }\end{array}$ & Ischaemic stroke & $\begin{array}{l}\text { 12,276, mean age } 73 \pm 13 \text {, } \\
\text { median NIHSS } 4 \text { (IQR } 2-9) .25 .1 \% \text { dysphagic }\end{array}$ & $\begin{array}{l}55,39,4.7 \text {, and } 1.5 \% \text { screened } \\
\text { within } 3,3 \text { to }<24,24 \text { to } \leq 72 \text {, and } \\
>72 \text { h from admission }\end{array}$ \\
\hline $\begin{array}{l}\text { Arnold et al. [27], } \\
2016\end{array}$ & $\begin{array}{l}\text { Prospective } \\
\text { observational, } \\
\text { Switzerland }\end{array}$ & Ischaemic stroke & $\begin{array}{l}\text { 570, mean age } 65.1 \text { (range } 19.6-94.7 \text { ), } \\
\text { mean NIHSS dysphagia } 9.8 \pm 7.0 \text { vs. } 4.5 \pm 5.1 \\
\text { non-dysphagia }\end{array}$ & $<24 \mathrm{~h}$ from admission. \\
\hline $\begin{array}{l}\text { Bray et al. [28], } \\
2017\end{array}$ & $\begin{array}{l}\text { Prospective } \\
\text { observational, } \\
\text { UK }\end{array}$ & $\begin{array}{l}\text { Ischaemic and } \\
\text { haemorrhagic } \\
\text { stroke }\end{array}$ & $\begin{array}{l}\text { 63,650, median age } 77(67-85), \text { Mdn NIHSS } 4 \\
\text { (IQR 2-9), 38.6\% dysphagic }\end{array}$ & $\begin{array}{l}\text { median time }<2.9 \mathrm{~h} \text { from } \\
\text { admission (IQR } 1.3-5.7 \mathrm{~h})\end{array}$ \\
\hline $\begin{array}{l}\text { Hinchey et al. [29], } \\
2005\end{array}$ & $\begin{array}{l}\text { Prospective } \\
\text { observational, } \\
\text { USA }\end{array}$ & Ischaemic stroke & $\begin{array}{l}\text { 2,532, average age (SD) } 70.5(14), \\
\text { mean NIHSS } 7.2(95 \% \text { CI } 6.8-7.5) \neq\end{array}$ & $\begin{array}{l}\text { Pre oral intake in } 61 \%(95 \% \text { CI } \\
50-72) ; \text { range at individual sites } \\
22-100 \%\end{array}$ \\
\hline $\begin{array}{l}\text { Hoffmeister et al. } \\
{[33], 2013}\end{array}$ & $\begin{array}{l}\text { Retrospective } \\
\text { observational, } \\
\text { Chile }\end{array}$ & Ischaemic stroke & $\begin{array}{l}677, \text { mean women age } 69.8(95 \% \text { CI } 68-71.6) \text {, } \\
66.3 \text { men years }(95 \% \text { CI } 68.0-71.6)^{\dagger \ddagger}\end{array}$ & $<48 \mathrm{~h}$ admission \\
\hline $\begin{array}{l}\text { Joundi et al. [30], } \\
2017\end{array}$ & $\begin{array}{l}\text { Prospective } \\
\text { observational, } \\
\text { Canada }\end{array}$ & Ischaemic stroke & $\begin{array}{l}6,677 \text {, age } 80+\text { years } 34.0 \% \text { not screened vs. } 41 \% \\
\text { screened, mean NIHSS } 4.29 \text { not screened vs. } 7.9 \\
\text { screened, } 47.8 \% \text { dysphagic* }\end{array}$ & $80.8 \% \leq 72 \mathrm{~h}$ from admission \\
\hline $\begin{array}{l}\text { Maeshima et al. } \\
\text { [37], } 2014\end{array}$ & $\begin{array}{l}\text { Prospective } \\
\text { observational, } \\
\text { Japan }\end{array}$ & Ischaemic stroke & 292 , mean age (SD) 69.9 $\pm 12.2,71.6 \%$ dysphagic $^{\dagger}$ & $1.7 \pm 1.7$ days from stroke onset \\
\hline $\begin{array}{l}\text { Odderson et al. } \\
{[35], 1995}\end{array}$ & $\begin{array}{l}\text { Prospective } \\
\text { observational, } \\
\text { USA }\end{array}$ & Ischaemic stroke & $\begin{array}{l}\text { 124, age of dysphagic } 75.2 \pm 1.5 \text { vs. } 75.3 \pm 1.4 \\
\text { non-dysphagic. } 38.7 \% \text { dysphagic* }{ }^{*}\end{array}$ & $<24 \mathrm{~h}$ of admission \\
\hline $\begin{array}{l}\text { Odderson and } \\
\text { McKenna [36], } \\
1993\end{array}$ & $\begin{array}{l}\text { Prospective } \\
\text { observational, } \\
\text { USA }\end{array}$ & Ischaemic stroke & 121 , average age $73.9^{\dagger \ddagger}$ & $<24$ h of admission \\
\hline $\begin{array}{l}\text { Palli et al. [31], } \\
2017\end{array}$ & $\begin{array}{l}\text { Quasi } \\
\text { experimental, } \\
\text { Austria }\end{array}$ & Ischaemic stroke & $\begin{array}{l}\text { 384, mean age } 72.3 \pm 13.7 \\
\text { mean NIHSS } 3,37.5 \% \text { dysphagic }\end{array}$ & $\begin{array}{l}\text { Median } 7 \text { h (range } 1-69 \text { ) } \\
\text { (intervention group) }\end{array}$ \\
\hline $\begin{array}{l}\text { Perry and } \\
\text { McLaren [32], } \\
2000\end{array}$ & $\begin{array}{l}\text { Quasi } \\
\text { experimental } \\
\text { design, UK }\end{array}$ & Acute stroke & $\begin{array}{l}400, \text { mean age }(\mathrm{SD}) \text { pre-test } 73.4(12.6) / 71.6(13.3) \\
\text { post-test, median NIHSS pre-test } 7 \text { (IQR } 5-12) / \\
\text { post-test } 8 \text { (IQR } 4-13), \% \text { dysphagia } 43.1 \% \text { post-test } \\
\text { vs. } 41.6 \% \text { pre test }\end{array}$ & $\begin{array}{l}<24 \text { h from admission. } 74.5 \% \\
\text { screened } \leq 24 \mathrm{~h} \text { in post-test vs. } \\
57.3 \% \text { pre test, } p<0.001\end{array}$ \\
\hline $\begin{array}{l}\text { Smithard et al. } \\
\text { [34], } 1996\end{array}$ & $\begin{array}{l}\text { Prospective } \\
\text { observational, } \\
\text { UK }\end{array}$ & Acute stroke & $\begin{array}{l}\text { 121, median age } 79 \text { (range } 40-93) \\
50 \% \text { dysphagic }^{\dagger}\end{array}$ & Days $0-3,7$ \\
\hline
\end{tabular}

determining the reliability of results ranged from levels of significance only $(p \leq 0.05)$ [31], to OR [26, 29,37], and adjusted OR (aOR) $[28,30,33]$. The confidence intervals for the association between dysphagia screening and SAP in the Chilean [33] and Japanese [37] studies (online suppl. Appendices) suggested uncertainty about the precision of the results.

\section{Type and Methods of Dysphagia Screening}

Three studies reported more than one type of screening method involving a combination of informal, formal and standardised assessments $[29,30,32]$. The Toronto Bedside Swallowing Screening Test was most frequently used in the Canadian registry-based study [30]. Perry and McLaren found the Standardised Swallow Assessment 


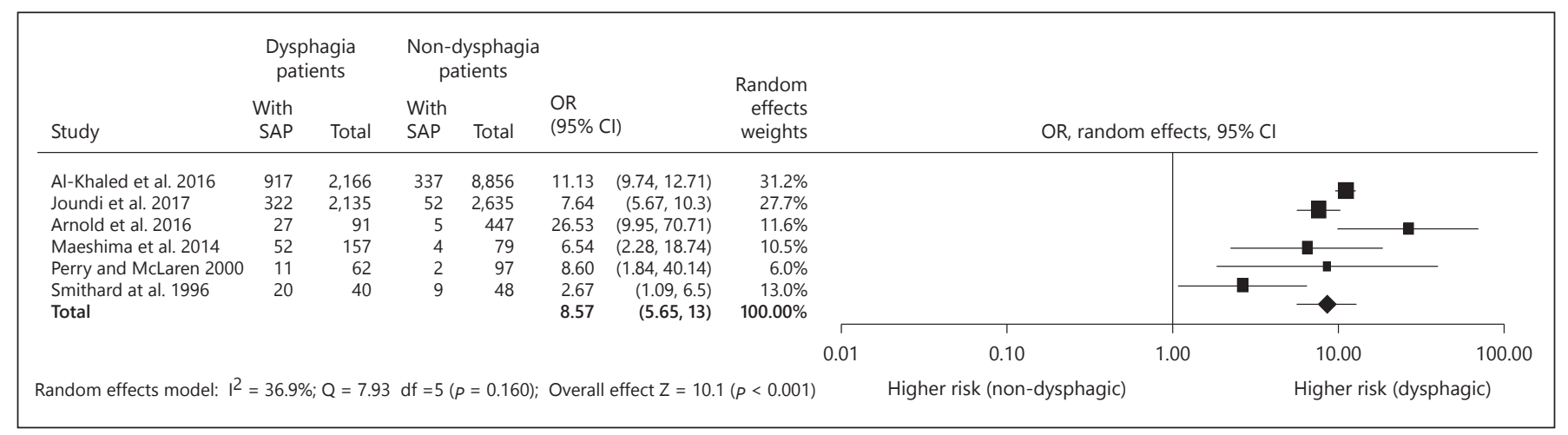

Fig. 2. OR of SAP in dysphagia versus non-dysphagia patients.

(SSA) was the most common method in their post-test group [32]. Two studies used the Gugging Swallow Screen (GUSS) [27, 31]. Smithard et al. [34] used their own validated Bedside Swallow Assessment. Maeshima et al. [37] used a repetitive saliva swallow test and modified water test. Two studies used locally developed screens [26, 35] and 2 did not describe the screening process or specify the DSP $[33,36]$. In the largest study, the dataset lacked information on the nature of the DSP used [28].

Screening was undertaken by nurses, physicians and physiotherapists with special training in dysphagia and SLPs. Methods of screening followed a stepwise procedure, which began with an indirect swallowing test or risk assessment followed by a direct swallow assessment with water and, in some studies, diet consistencies. Four studies involved an indirect and a direct swallow test with water only [29, 32, 34, 37]; this is consistent with the Toronto Bedside Swallowing Screening Test [30]. One study involved only direct assessment with water and/or thickened apple juice and an additional swallowing and cough provocation test to detect for silent aspiration [26]. The GUSS involves an indirect and direct swallow assessment with water, semi-solid and solid diet consistencies [27, 30]. Odderson et al. [35] described a similar approach.

\section{Frequency and Time of Screening}

The percentage patients who were screened ranged from 12.1 to $100 \%$. Differences were due to screening only participants perceived to be at risk, adherence to local protocols and study design. In 4 [26, 28-30] out of the 5 stroke registries, the incidence of screening ranged from 61 to $87.7 \%$. All patients underwent a screen in the Bernese Stroke Registry study [27]. Hinchey et al. [29] found adherence to dysphagia screening was higher in hospitals with a formal DSP compared to those without (78 vs.
56\%), and formal dysphagia screening was associated with increased adherence to completing the screen before oral intake. Time of screen is shown in Table 1.

\section{Type and Methods of Specialist Swallow Assessment}

Six studies reported patients seen for a clinical swallow assessment or consultation by a SLP [28-30, 32, 35] or equivalent trained professional [26]. No studies reported use of a validated assessment. There was limited information on what comprised a specialist swallow assessment (online suppl. Appendices). Two studies $[31,36]$ used the terms SLP "screening" and "assessment" interchangeably but did not provide information on what each involved. Odderson et al. [35] reported that where a patient did not meet the criteria for safe swallowing, swallowing evaluation was completed by an SLP and reviewed daily. AlKhaled et al. [26] reported that if swallowing difficulties were suspected following the screen, further dysphagia tests were performed.

\section{Frequency and Time of Assessment}

The proportion of patients who had an SLP assessment varied between studies. Bray et al. [28] found 39\% of all patients had an SLP assessment contrasting with Odderson and McKenna [36] 87\% assessed and subsequently treated (61\%). Hinchey et al. [29] stated 22\% received an SLP bedside or formal examination. Joundi et al. [30] reported $77 \%$ of patients who had a documented screen were assessed by SLP.

Four studies provided information on when patients were seen by an SLP [28, 31, 32, 36]. Bray et al. [28] reported $39 \%$ had an SLP assessment $22.9 \mathrm{~h}$ post admission (median; IQR 6.2-49.4 h). Perry and McLaren [32] reported that, in the post-test study group, $56 \%$ were assessed within $72 \mathrm{~h}$ compared to $39 \%$ in the pre-test group 
$(p<0.058)$. Odderson and McKenna [36] reported an SLP assessment on Day 2. On Day 5, a decision was made about the need for alternative nutritional support, for example, percutaneous gastronomy tube (PEG). Palli [31] reported that prior to the implementation of 24/7 nurse screening, patients had a swallow assessment 20 hours from admission (range $1-183 \mathrm{~h}$ ).

Three studies referred to instrumental investigations or contrast radiography [27, 34, 37]; Smithard et al. [34] performed VFS when possible within $24 \mathrm{~h}$ of the bedside assessment, and further dysphagia evaluation was performed by VFS or FEES as part of the GUSS if a patient scored $<5$ points. No information was provided on number of patients for these investigations. Maeshima et al. [37] reported contrast radiography was performed if any abnormality in bedside swallow assessment or pulmonary aspiration with oral intake was suspected but did not provide information on how often this occurred.

\section{Type and Methods of Dysphagia Management}

Nine studies [26, 27, 29, 30, 32, 34-37] referred to types and methods of dysphagia management during the acute stroke phase. The level of detail was limited. Types of management included direct, indirect and compensatory strategies. Examples of direct strategies were NBM with enteral or parenteral feeding/fluids $[26,27,29,30$, $32,34-37]$, if the swallow was unsafe, or if supplementary nutrition/hydration of oral intake was insufficient, therapeutic eating of small amounts, diet modification, and adjusted posture [29, 32, 35, 37]. Indirect strategies included oral care, oral articulation exercises, and pharynx cooling stimulation [37]. Compensatory strategies included chin tuck, head rotation, and multiple swallowing [37]. Al-Khaled et al. [26] referred to SLP initiating measures of therapy but did not describe what this involved.

\section{Definition and Diagnosis of Pneumonia}

The Centers for Disease Control and Prevention (CDC) criteria [38] were used to define pneumonia in 3 out of 12 studies (online suppl. Appendices) [27, 29, 37]. One study [31] used the PISCES SAP diagnostic criteria [1]. Four used a combination of clinical symptoms, signs and radiologic findings on X-ray and laboratory results $[27,30,32,34]$. The definition for 4 studies was based on clinician initiation of antibiotics [28, 32-34]. Odderson et al. [35] referred to criteria for aspiration pneumonia but did not define the criteria. Odderson and McKenna [36] provided no definition.
Information on measurement of when pneumonia was reported varied. Most studies reported pneumonia during hospitalization $[26,27,29,31-33,35,36]$. Two studies reported within 7 days of admission $[28,34]$. Maeshima et al. [37] reported pneumonia pre/post $72 \mathrm{~h}$ of admission and one study reported within 30 days of hospitalisation [30].

\section{Incidence of SAP}

Overall incidence was reported in 8 studies [26-29, 33, 35-37] (online suppl. Appendices) and ranged from 0 to $23.6 \%[35,33]$, with the largest population at $8.7 \%$ [28]. Maeshima et al. [37] found $26.9 \%$ developed SAP had early onset pneumonia with development of pneumonia within $72 \mathrm{~h}$ of admission. Six studies compared rates of pneumonia between dysphagia and non-dysphagia patients $[26,27,30,32,34,37]$. Patients with dysphagia were at increased risk of SAP compared to patients without dysphagia (OR 8.57; 95\% CI 5.65-13; Fig. 2). Five studies found that implementing a formal DSP or clinical pathway significantly reduced pneumonia rates $[29,31,32,35$, 36]. Odderson and McKenna [36] found implementing a clinical pathway which involved an integrated team with immediate rehabilitation improved rates of pneumonia.

\section{Associations between SAP and Dysphagia Screening}

Six studies analysed associations between dysphagia screening and SAP [26, 28-30, 33, 37]. Hinchey et al. [29] found that the pneumonia rate was significantly higher in those who had any screen versus those who did not $(p<$ 0.0001 ). Joundi et al. [30] found patients who failed dysphagia screening were more likely to develop pneumonia (aOR 4.71; 95\% CI 3.43-6.47) and aspiration pneumonia (aOR 6.5; 95\% CI 4.2-9.9) compared to those that passed. Maeshima et al. [37] found that an abnormal screen was associated with SAP (OR 2.65; 95\% CI 0.90-9.72; $p=$ 0.0774). Hoffmeister et al. [33] found no association between dysphagia screening and pneumonia (aOR 1.58 95\% CI $0.60-4.15 ; p=0.36$ ). However, neither of these results was statistically significant $[33,37]$.

Three studies analysed the effect of early dysphagia screening (EDS) and patients developing pneumonia. Palli et al. [31] found that $24 / 7$ dysphagia screening outside the working hours of SLP significantly reduced time to dysphagia screening from median 20 to $7 \mathrm{~h}(p=0.001)$. Two studies found risk of developing SAP was increased with late dysphagia screening $[26,28]$. EDS $(<24 \mathrm{~h}$ of admission) was independently associated with decreased risk of SAP (OR 0.68; 95\% CI 0.52-0.89) [26]. Bray et al. [28] found a modest association between time from ad- 
mission and time to dysphagia screen with the longest delays in screening having $36 \%$ higher odds of SAP compared to those in the first quartile.

\section{Associations between SAP and Specialist Swallow Assessment}

Bray et al. [28] found a strong independent relationship between delay in SLP assessment and incidence of SAP. Delays in SLP assessment were associated with an absolute increase in the risk of SAP of 3\% over the first $24 \mathrm{~h}$. Delays in SLP assessment $>24 \mathrm{~h}$ were associated with an additional $4 \%$ absolute increase in SAP. Patients in the slowest quartile had 1.98 (1.67-2.35) odds of SAP compared with patients receiving the quickest SLP assessment. Smithard et al. [34] found no evidence to justify the routine use of VFS in screening for aspiration in acute stroke.

Associations between SAP and Dysphagia Management

Alternative feeding was the only management strategy where data were analysed in relation to SAP. Arnold et al. [27] found dysphagia tube-fed compared to dysphagia non-tube patients had higher risk for in-hospital pneumonia and need of antibiotic treatment. After adjusting for confounding variables, the association between tube placement and pneumonia was not statistically significant (OR 2.2; 95\% CI 0.89-5.5; $p=0.087$ ). Maeshima et al. [37] found $53.8 \%$ of patients who developed SAP were NBM with nasogastric and enteral feeding and developed SAP after $72 \mathrm{~h}$. These patients and those who developed early onset pneumonia had the most severe neurological syndromes and cognitive dysfunctions.

\section{Discussion}

A recently published review found insufficient evidence to determine the effect of DSP [39]. However Smith et al. [39] included only randomized controlled trials and did not focus specifically on pneumonia as an outcome. Our review found emerging evidence that EDS is associated with lower incidence of SAP and supports current guidelines that all patients should be screened for dysphagia on admission before oral intake. There may be reason for performing later screening in patients with altered consciousness [26]. In studies that examined association between dysphagia screening and development of SAP, a range of screening practices was used, thereby precluding the recommendation of a particular protocol. A formal written protocol improved adherence and demonstrated higher numbers of patients being screened. An integrated team

Dysphagia Assessment and Management on Risk of Stroke-Associated Pneumonia approach and clinical pathway also improved rates of pneumonia.

Delays in SLP assessment were associated with SAP with an absolute risk of pneumonia incidence of $1 \%$ per day of delay. There was limited information about the assessment components. One study evaluated the role of VFS to screen for aspiration, one of the main risk factors for SAP. There was no evidence to support its routine use during the first $72 \mathrm{~h}$ of admission. Limited use of VFS in the acute phase post stroke is expected, given patients may be too acutely unwell to leave the ward. No study reported the use of FEES, which has the advantage of administration at the bedside, is cost effective and with no radiation exposure can be repeated if clinically indicated. When used selectively, FEES has been shown to reduce pneumonia rates, improve functional outcomes and is therefore receiving increasing support in acute stroke dysphagia assessment $[40,41]$. Strokerelated dysphagia may be graded using endoscopic scales such as the Fibre Optic Endoscopic Dysphagia Severity Scale $[42,43]$ or Penetration-Aspiration Scale [44].

The potential for tube feeding to contribute to infection by promoting oral-pharyngeal colonisation or aspiration, and other factors such as poor oral and dental hygiene, requiring assistance with mobility, positioning, and concurrent chest and cardiac disease, have been identified as potential risk factors for SAP [45, 46]. Further research about the association between these factors and dysphagia patients developing SAP would improve our understanding of their impact during the first $72 \mathrm{~h}$ of admission and potentially improve patient outcomes.

No randomized controlled trials examining a specific DSP or specialist swallow assessments and the impact on SAP was found. The heterogeneity of study designs, reporting methods and the large size of one study [28] precluded meta-analysis. Caution is recommended in drawing overall conclusions and generalising. Future reporting would benefit from a more standardised approach to allow meta-analyses.

\section{Conclusion}

This review found increasing evidence that early dysphagia screening and specialist swallow assessment help to reduce the odds of SAP. Variation in assessment methods and management factors (e.g., tube feeding) may be associated with SAP. Further understanding is needed on the effect of these variations and other confounding factors, which may contribute to the development of SAP during this acute phase.

Cerebrovasc Dis 2018;46:97-10 


\section{Disclosure Statement}

close.

Authors declare that they have no conflicts of interest to dis-

\section{References}

1 Smith JC, Kishore KA, Vail A, Chamorro A, Garau J, Hopkins JS, et al: Diagnosis of strokeassociated pneumonia: recommendations from the pneumonia in stroke consensus group. Stroke 2015;46:2335-2340.

2 Kishore KA, Vail A, Chamorro A, Garau J, Hopkins SJ, Di Napoli M, et al: How is pneumonia diagnosed in clinical stroke research? A systematic review and meta-analysis. Stroke 2015;46:1202-1209.

3 Westendorp WF, Nederkoorn PJ, Vermeij J, Dijkgraaf MG, van de Beek D: Post-stroke infection: a systematic review and meta-analysis. BMC Neurol 2011;11:110.

4 Finlayson O, Kapral M, Hall R, Asllani E, Selchen D, Saposnik G: Risk factors, inpatient care, and outcomes of pneumonia after ischemic stroke. Neurology 2011;77:1338-1345.

5 Katzan IL, Dawson NV, Thomas CL, Votruba ME, Cebul RD: The cost of pneumonia after acute stroke. Neurology 2007;68:1938-1943.

6 Emsley HC, Hopkins SJ: Acute ischaemic stroke and infection: Recent and emerging concepts. Lancet Neurol 2008;7:341-353.

7 Hannawi Y, Hannawi B, Rao CP, Suarez JI, Bershad EM; Stroke-Associated Pneumonia: Major advances and obstacles. Cerebrovasc Dis 2013;35:430-443.

8 Martino R, Foley N, Bhogal S, Diamant N, Speechley M, Teasell R: Dysphagia after stroke: Incidence, diagnosis, and pulmonary complications. Stroke 2005;36:2756-2763.

9 Intercollegiate Stroke Working Party. National Clinical Guideline for Stroke. Fifth Edition. 2016. London, Royal College of Physicians. https://www.strokeaudit.org/Guideline/Full-Guideline.aspx (June 27, 2017).

10 Jauch EC, Saver JL, Adams HP Jr, Bruno A, Connors JJ, Demaerschalk BM, et al; American Heart Association Stroke Council; Council on Cardiovascular Nursing; Council on Peripheral Vascular Disease; Council on Clinical Cardiology: Guidelines for the early management of patients with acute ischemic stroke: a guideline for healthcare professionals from the American Heart Association/ American Stroke Association. Stroke 2013;44: 870-947.

11 Casaubon LK, Boulanger JM, Blacquiere D, Boucher S, Brown K, Goddard T, et al; Heart and Stroke Foundation of Canada Canadian Stroke Best Practices Advisory Committee: Canadian stroke best practice recommendations: hyperacute stroke care guidelines, $\mathrm{Up}$ date 2015. Int J Stroke 2015;10:924-940.

12 Clinical Guidelines for Stroke Management. 2017. https://informme.org.au/Guidelines/

\section{Funding Sources}

This work was supported by the Stroke Association (SE-TSA PGF 2017/03).
Clinical $\% 20$ Guidelines $\% 20$ for $\% 20$ Stroke\%20Management\%202017 (September 25, 2017)

13 European Stroke Organisation (ESO) Executive Committee; ESO Writing Committee: Guidelines for management of ischaemic stroke and transient ischaemic attack. Cerebrovasc Dis 2008;25:457-507.

14 Daniels SK, Anderson JA, Willson PC: Valid items for screening dysphagia risk in patients with stroke: a systematic review. Stroke 2012; 43; 892-897.

15 McAllister S, Kruger S, Doeltgen S, Tyler-Boltrek E: Implications of variability in clinical bedside swallowing assessment practices by speech language pathologists. Dysphagia 2016;31:650-662.

16 Mann G, MASA: The Mann assessment of swallowing ability. Clifton, NY, Thomson Learning Inc., 2002.

17 NIHR Centre for Reviews and Dissemination - CRD Database. https://www.crd.york. ac.uk/CRDWeb/ (October 14, 2017).

18 Moher D, Liberati A, Tetzlaff J, Altman DG; PRISMA Group: Preferred reporting items for systematic reviews and meta-analyses: the PRISMA statement. PLoS Med 2009;6: e1000097.

19 Centre for Reviews and Dissemination. Systematic Reviews: Guidance for Undertaking Reviews in Healthcare. https://www.york.ac. $\mathrm{uk} / \mathrm{media} / \mathrm{crd} /$ Systematic_Reviews.pdf (October 14, 2017)

20 Booth A: Unpacking your literature search toolbox: on search styles and tactics. Health Info Libr J 2008;25:313-317.

21 Intercollegiate Stroke Working Party: National Clinical Guideline for Stroke. Evidence Tables. London, Royal College of Physicians. https://www.strokeaudit.org/Guideline/Appendices.aspx (accessed October 18, 2017).

22 Critical Appraisal Skills Programme (CASP) CASP Checklists. http://www.casp-uk.net/ checklists (accessed October 18, 2017).

23 National Heart, Lung and Blood Institute. Quality Assessment Tool for Before and After (Pre-Post) Studies with No Control Group. https://www.nhlbi.nih.gov/health-pro/ guidelines/in-develop/cardiovascular-riskreduction/tools/before-after (accessed October 18,2017$)$

24 DerSimonian R, Laird N: Meta-analysis in clinical trials. Control Clin Trials 1986;7:177188.

25 Neyeloff JL, Fuchs SC, Moreira LB: Metaanalyses and Forest plots using a microsoft excel spreadsheet: step-by-step guide focus- ing on descriptive data analysis. BMC Research Notes 2012;5:52.

26 Al-Khaled M, Matthis C, Binder A, Mudter J, Schattschneider J, Pulkowski U, et al: Dysphagia in patients with acute ischemic stroke: early dysphagia screening may reduce stroke-related pneumonia and improve stroke outcomes. Cerebrovasc Dis (Basel, Switzerland) 2016;42:81-89.

27 Arnold M, Liesirova K, Broeg-Morvay A, Meisterernst J, Schlager M, Mono ML, et al: Dysphagia in acute stroke: incidence, burden and impact on clinical outcome. PLos One 2016;11:2.

28 Bray BD, Smith CJ, Cloud GC, Enderby P, James M, Paley L, et al: The association between delays in screening for and assessing dysphagia after acute stroke, and the risk of stroke-associated pneumonia. J Neurol Neurosurg Psychiatry 2017;88:25-30.

29 Hinchey JA, Shephard T, Furie K, Smith D, Wang D, Tonn S: Formal dysphagia screening protocols prevent pneumonia. Stroke 2015; 36:1972-1976.

30 Joundi RA, Martino R, Saposnik G, Giannakeas V, Fang J, Kapral MK: Predictors and outcomes of dysphagia screening after acute ischemic stroke. Stroke 2017;48:900-906

31 Palli C, Fandler S, Doppelhofer K, Niederkorn K, Enzinger C, Vetta C, et al: Early dysphagia screening by trained nurses reduces pneumonia rate in stroke patients: a Clinical Intervention Study. Stroke 2017;48:25832585.

32 Perry L, McLaren SM: An evaluation of implementation of evidence-based guidelines for dysphagia screening and assessment following acute stroke: phase 2 of an evidencebased practice project. J Clin Excellence 2000; 2:147-156

33 Hoffmeister L, Lavados PM, Comas M, Vidal C, Cabello R, Castells X: Performance measures for in-hospital care of acute ischemic stroke in public hospitals in Chile. BMC Neurol 2013;13:23.

34 Smithard DG, O’Neill PA, Parks C, Morris J: Complications and outcome after acute stroke. does dysphagia matter? Stroke1996; 27:1200-1204.

35 Odderson IR, Keaton JC, McKenna BS: Swallow management in patients on an acute stroke pathway: Quality is cost effective. Arch Phys Med Rehab 1995;76:1130-1133.

36 Odderson IR McKenna BS: A model for management of patients with stroke during the acute phase: outcome and economic implications. Stroke 1993;24:1823-1827. 
37 Maeshima S, Osawa A, Hayashi T, Tanahashi $\mathrm{N}$ : Elderly age, bilateral lesions, and severe neurological deficit are correlated with stroke-associated pneumonia. J Stroke Cerebrovasc Dis 2014;23:484-489.

38 Horan TC, Andrus M, Dudeck MA: CDC/ NHSN surveillance definition of health careassociated infection and criteria for specific types of infections in the acute care setting. AJIC 2008;36:309-332.

39 Smith EE, Kent DM, Bulsara KR, Leung LY, Lichtman JH, Reeves MJ, Tow ghi A, Whiteley $\mathrm{WN}$, Zahuranec $\mathrm{DB}$; on behalf of the American Heart Association Stroke Council: Effect of dysphagia screening strategies on clinical outcomes after stroke: a systematic re- view for the 2018 guidelines for the early management of patients with acute ischemic stroke. Stroke 2018;49:e123-e128.

40 Bax L, McFarlane M, Green E, Miles A: Speech-language pathologist-led fiberoptic endoscopic evaluation of swallowing: functional outcomes for patients after stroke. J Stroke Cerebrovasc Dis 2014;23:e195-e200.

41 Leder SB, Espinosa JF: Aspiration risk after acute stroke: comparison of clinical examination and fiberoptic endoscopic evaluation of swallowing. Dysphagia 2002;17:214-218.

42 Warnecke T, et al: Fiberoptic endoscopic dysphagia severity scale redicts outcome after acute stroke. Cerebrovasc Dis 2009;28:283289.
43 Warnecke T, et al: Aspiration and dysphagia screening in acute stroke - the Gugging Swallowing Screen revisited. Eur J Neurol 2017;24: 594-601.

44 Colodny N: Interjudge and intrajudge reliabilities in fiberoptic endoscopic evaluation of swallowing (fees) using the penetration-aspiration scale: a replication study. Dysphagia 2002;17:308-315.

45 Beavan J: Update on management options for dysphagia after acute stroke. Br J Neurosci Nurs 2015;11:10-19.

46 Brogan E, Brookes K, Langdon C, Budgeon C, Blacker D:Can'tswallow, can't transfer, can't toilet: factors predicting infections in the first week post stroke. J Clin Neurosci 2015;22:1:92-97. 